\title{
Herbal Home Remedies for Toothache during the COVID-19 Pandemic: A
}

\section{Review}

Available online at www.hjhs.co.in

\section{REVIEW ARTICLE}

\author{
Abhishek Kumar*, Akash Kumar Giri, Bibek Kattel \\ College of Dental Surgery, B.P. Koirala Institute of Health Sciences, Dharan, Nepal
}

DOI 10.22270/hihs.v6i3.104

\begin{abstract}
The COVID-19 pandemic resulted in the halt of proper dental care in most of the world, except for emergency cases. And, this resulted in a lot of people seek some home remedies for relieve in dental pain. So, this article aims to list down herbal home remedies which can be very helpful in such conditions. The use of medicinal herbs for dental pain can be traced back to history in some form or the other in almost every country. These herbal home remedies have no significant side effects as compared to other chemical-based alternatives, are also easy to obtain and cheaper as well. Clove, Olive, Miswak, Babool and other herbs listed in the article have significant dental properties which have been validated scientifically through various researches. These plant products can be hence used in commercial products as well but only after proper clinical trials. Further research should be encouraged in this field as herbal alternatives can be very beneficial with no such side effects. However, these home remedies are only useful for symptomatic treatment and undergoing proper dental care is advised.
\end{abstract}

Keywords: Coronavirus Disease 2019 (COVID-19); Home Remedies; Herbal; Toothache.

\section{Introduction}

The COVID-19 pandemic resulted in the halt of proper dental care in most of the world, except for emergency cases. And, this resulted in a lot of people seek some home remedies for relieve in dental pain. So, this article aims to list down herbal home remedies which can be very helpful in such conditions. The use of medicinal herbs for dental pain can be traced back to history in some form or the other in almost every country. These herbal home remedies have no significant side effects as compared to other chemical-based alternatives, are also easy to obtain and cheaper as well. Clove, Olive, Miswak, Babool and other herbs listed in the article have significant dental properties which have been validated scientifically through various researches. These plant products can be hence used in commercial products as well but only after proper clinical trials. Further research should be encouraged in this field as herbal alternatives can be very beneficial with no such side effects. However, these home remedies are only useful for symptomatic treatment and undergoing proper dental care is advised.

Toothache is defined as an orofacial pain originated from a dental element and/or adjacent structures in consequence of several diseases or conditions, like a cavity, periodontitis, trauma, occlusal dysfunction, and abscess. (1) Toothache results from a variety of etiologies, both odontogenic and non-odontogenic. (2) Dental pain may occur at any age, in any gender, and any geographic region. (3) Because of the pandemic spread of COVID-19 have made people be under lockdown situations in many parts of cities and rural areas the public gathering is prohibited to control the virus spread. In this situation, even dental clinics are closed. For mild tooth pain, the people visiting the doctor can minimize the spread of infection. So, in this situation, home remedies can play a key role in minimizing dental pain and spread of infection. (4)

The use of medicinal herbs for dental pain can be traced back to history in some form or the other in almost every country. According to the WHO, the use of 
medicinal plants as remedies is somewhere between $65 \%$ and $80 \%$ of the populations of developing countries in rural areas (5) and the use of traditional medicine is expanding at a rapid pace all across the world. (6) The use of clove, olive, turmeric and many other herbs for dental pain relief has been mentioned in the Ayurvedic literature. (7) The Meena community in Rajasthan, India also has a history of using folk herbal medicine for the treatment of Toothache. (8) Bryophyllum pinnatum (9), Capsicum frutescens (10), Argemone Mexicana L. has been used in Mexican dentistry as a traditional herbal medicine for dental pain. (11) In the Ivory Coast, Parkia biglobosa (Mimosaceae) is used in traditional medicine as an analgesic drug, against dental pain. (12) A total of 130 medicinal plants have been reported for the treatment of Toothache in Ethiopia. (13) However, home remedies simply treat the symptoms, to reduce discomfort and pain and cannot be used as a substitute for dental treatment, few of them do have some scientific basis. Further clinical trials are required for the appropriate use of these herbal remedies on a commercial basis. Lately, there has been a rise in the demand for herbal products in every sector, so these herbs can result in commercially successful products as well. These home remedies can prove to be of great significance in this time of COVID19 pandemic when we all can play a huge role in containing this viral outbreak by not stepping out because these herbal alternatives can help us with a mild toothache.

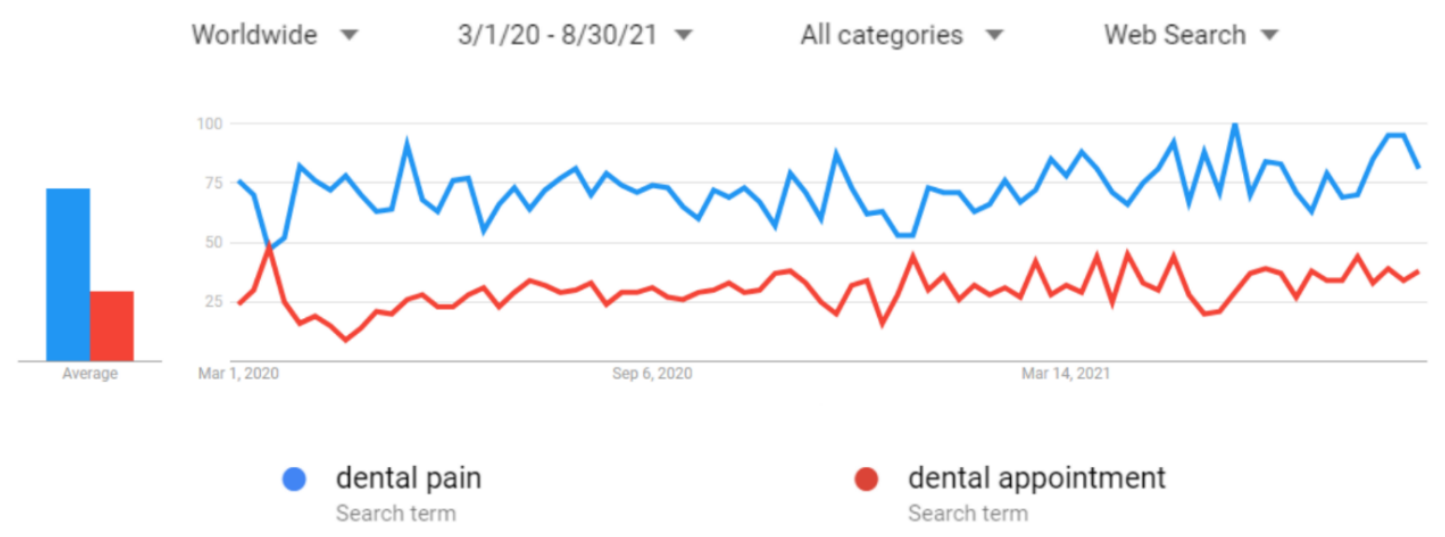

Figure. 1: A graph of worldwide google search trends from $1^{\text {st }}$ March of 2020 to $30^{\text {th }}$ August of 2021 showing an appreciable increase in search interest for "dental pain" and a decrease in searches for "dental appointment".

The outbreak of COVID-19 and its impact on our daily lives is rapidly evolving. This pandemic has presented new challenges for dentistry. Most of the procedures performed in a dental clinic have the potential to create contaminated aerosol and splatters. Dental handpieces, ultrasonic scalers, and the air-water syringes used in common dental practice are capable of producing aerosols, which are usually a mix of air and water derived from these devices and the patient's saliva.
(14) The pandemic has made it difficult to practice dentistry even if we follow all the newly prescribed guidelines (hand hygiene, PPE, strategies and caution in performing aerosol-generating procedures) because there's always a chance of transmission which can result in an increased spread of the virus. Almost all of the major dental associations have urged dental offices to treat only emergency patients. The safety of the dental team and patients or people accompanying patients 
is essential while treating emergency patients and following this crisis. The ADA (American Dental Association) has recently developed a guideline that can help us in determining a patient's need for urgent or emergency care. (15)

We can also see an increase in the Google search trends for 'dental pain' and a decrease in 'dental appointment' from mid of March 2020 (Fig.1). The lockdown came into significance from around the mid of March 2020, hence the changes in the graph are pretty visible. The search trends were based on the worldwide search from 1st March 2020 to 30th August 2021 in all categories under web search. This shows that people faced dental problems in the lockdown, but there wasn't proper dental health service available for them. Some patients even attempted to treat themselves at home in extreme circumstances. (16) So, this article aims to list down some home remedies for dental pain which can be easily followed by any individual, especially at this time of COVID-19 pandemic. The information provided in the article has been collected from trusted scientific sources to discuss the use of herbal medicine for dental disease and proper references have been provided wherever possible. These home remedies are for symptomatic treatment only, we suggest the patients seek proper health care in case of any dental emergency. Few herbal home remedies carrying significant dental properties have been hence listed below in the article.

\section{Herbal Home Remedies}

\section{Clove (Syzygium aromaticum)}

Clove oil has anti-microbial, antioxidant, anti-fungal, anti-viral, analgesic, local anaesthetic and anti-inflammatory activity. (17-20) Clove is used broadly in dental care for aid in toothache, sore gums and oral ulcers. Gargling with clove oil has been reported to be effective in sore throat conditions and halitosis. (21) The anodyne properties of clove oil on the dental pulp is well known but its overenthusiastic use can lead to mucosal irritation. (22) Clove oil might also be an effective anticarcinogenic agent due to its antioxidant properties as reported by Lee and Shibamoto; further research should be done to find out more about the anticarcinogenic activity of clove. (23) Eugenol, the principal chemical component of clove oil, is also used in the form of a paste or mixture as dental cement, filler and restorative material. (24)

Clove oil showed strong activity against periodontopathogenic bacteria, $F$. nucleatum, $P$. Intermedia, and $P$. Gingivalis. (24) Aneja and Joshi investigated the anti-microbial activity of clove oil against five dental caries causing microorganisms namely Streptococcus mutans, Staphylococcus aureus, Lactobacillus acidophilus (bacteria), Candida albicans and Saccharomyces cerevisiae (yeast) and the results indicated potent antimicrobial activity against the tested dental caries causing microorganisms. Clove oil emerged to be a potent agent exhibiting even better antibacterial and anti-fungal activity than Ciprofloxacin and Amphotericin-B respectively. (25)

However, clove oil is found to be toxic to human cells. If injected or ingested in sufficient amount, it has been shown to cause life-threatening complications, including ARDS (Acute Respiratory Distress Syndrome), Fulminant Hepatic Failure and CNS Disorders. (26)

\section{Olive (Olea europaea)}

Olive (Olea europaea) is an effective antimicrobial agent used for the treatment of Dental Pain. (27) Kumar et al. revealed that the stem extracts of $O$. europaea using petroleum ether, acetone, methanol, and water successively showed a broad spectrum of activity against microorganisms liable for foremost dental diseases. Methanol extracts of $O$. europaea showed the maximum activity against $S$. 
mutans and C. albicans. (28) Phytoconstituents analysis of the plant extract revealed the presence of alkaloids, flavonoids, glycosides, steroids, tannins, terpenoids and saponins which might be the reason behind its antimicrobial potential.

Similarly, the antimicrobial potential of five natural constituents of $O$. europaea (oleuropein, maslinic acid, hydroxytyrosol, oleocanthal, oleacein) was investigated against ten representative oral bacterial species and a Candida albicans strain, in which maslinic acid exerted the most significant inhibitory activity against the tested oral pathogens. (29) Olive oil is rich in oleic acid which is useful for enhancing the fluoride inhibition of EPS formation by $S$. mutans and has a role in preventing biofilm formation. (30) Therefore, olive oil may be useful in the prophylaxis of dental caries and periodontitis.

Olive oil can be used to prevent Dental erosion. Emersion of teeth in olive oil for 6 hours was found to be effective in reducing enamel erosion when exposed to citric acid $1 \%$ at $15 \mathrm{~min}$. (31) A study by Wiegand et al. aimed to analyse the impact of olive oil on enamel and dentin erosion, olive oil offered protection against enamel and dentin erosion when applied as $2 \%$ emulsion or $2 \%$ olive-oil-containing mouthrinse, but is not effective when applied as pure oil (100\%). (32)

Golestannejad et al. found out that the methanolic, ethanolic, and hydroalcoholic extracts of olive leaf extracts (OLE) have appropriate antibacterial activities due to their high phenolic content and can also reduce bacterial adhesion in dental plaque formation, as well as increases the $\mathrm{pH}$ of the oral environment. (33) Therefore, OLE can be used in the production of commercial products such as chewing gum, chocolate, and toothpaste to prevent dental caries.

\section{Babool (Acacia arabica)}

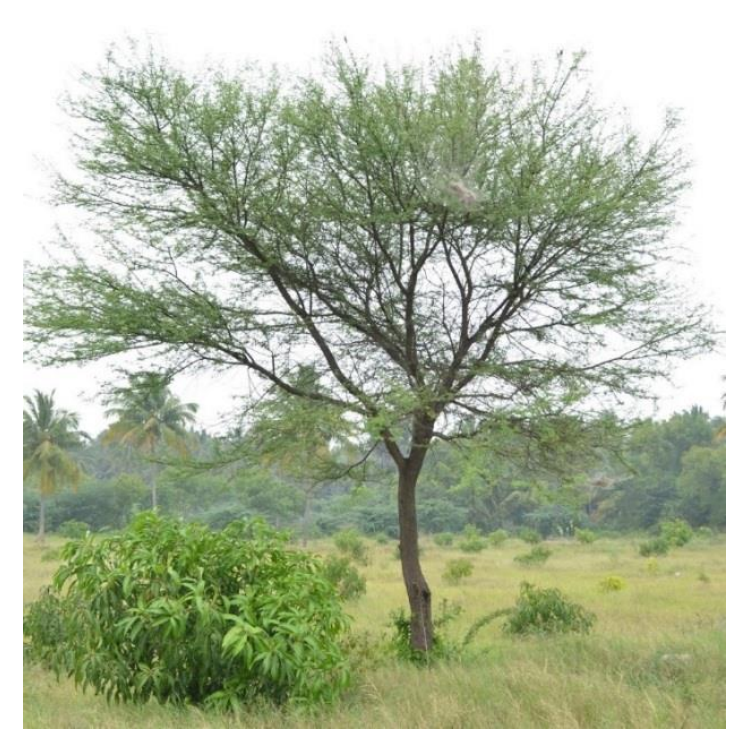

Figure. 2: Acacia arabica (Babool Tree)

The gum of Acacia arabica (Babool) has been studied for its effect on plaque and gingivitis and has been found to have the potential to inhibit early plaque formation and its action on suspected periodontal pathogens like $P$. gingivalis and $P$. intermedia has also been reported which is of significant clinical value. $(34,35)$ A. arabica leads to better clinical outcomes in patients with mild to moderate chronic periodontitis with effective chemical plaque control and antigingivitis action. (36,37) Clinical improvement in probing pocket depth, clinical attachment level, plaque index, gingival index and bleeding on probing has also been reported. (37) Based on all the findings, it is suggested that Acacia arabica-containing toothpaste could be a useful approach for prevention of gingivitis and that it may be as well recommended for daily oral hygiene procedures.

\section{Turmeric (Curcuma longa)}

Turmeric has a lot of roles to offer in dentistry. The benefits of turmeric include analgesic, antibacterial, anti-inflammatory, anti-tumour, anti-allergic, antioxidant, antiseptic, antispasmodic, astringent, cardiovascular, carminative, cholagogue, digestive, and diuretic properties. (38) Curcumin is the main constituent from 
clinical aspect which comprises around $0.3-5.4 \%$ of raw turmeric. It has been utilised broadly in Ayurvedic medication for quite a long time, as it is nontoxic and carries a variety of therapeutic properties. (39) Chlorhexidine gluconate as well as turmeric mouthwash can be utilized effectively as an adjunct to mechanical plaque control in prevention of plaque and gingivitis. (40) Turmeric mouthwash is well accepted by nearly all subjects without any significant side effects because of its bio-compatible nature.

$1 \%$ curcumin solution when used as subgingival irrigant result in better resolution of the inflammatory signs than chlorhexidine and saline irrigation. (41) Curcumin oil application resulted in healing of ulcers (RAS); there was also an early reduction in pain. (42) The topical application of turmeric at the site of injury also promotes healing of wounds. (43) So, turmeric can be used in varying forms for treating several ailments including surgical wounds.

In a study by Pandit et al., a fraction separated from turmeric showing antibiofilm activity was obtained having inhibitory effects on the virulence characteristics of $S$. mutans biofilms, such as bacterial adherence, aciduricity and acidogenicity. (44)

The use of turmeric is pretty varied in dentistry; it is also a dental-plaque staining agent. Plaques undergo staining in the dental-plaque detection system that also contains turmeric extracts and curcumin. (45)

Due to its free radical and antioxidant properties, turmeric inhibits the early stages of carcinogenesis. Turmeric arrests carcinomatous cells in the $\mathrm{G} 2 / \mathrm{M}$ phase of the cell cycle. (46) Thus, it can be useful against different types of malignancies. Besides, curcumin has reported in protecting healthy cells from the damaging effects of radiation and chemotherapy without decreasing the effectiveness of the therapy. (47)

\section{Neem (Azadirachta indica)}

Extracts from Neem sticks or bark have been shown to inhibit the growth of Streptococcus mutans and other Streptococcus species such as Streptococcus salivarius, Streptococcus mitis and Streptococcus sanguis and cause significant reductions in bacterial adhesion in vitro, suggesting that it can reduce the ability of some streptococci to colonize tooth surfaces and thus prevent further tooth decay. (48) Various studies have demonstrated that Neem (Azadirachta indica) based mouth rinses are highly efficacious and may be used as an alternative therapy in the treatment of Chronic Gingivitis and periodontal diseases. (49) Neem oil have bactericidal activity independent of the temperature and energy. This bactericidal activity is mainly due to the inhibition of cellmembrane synthesis in the bacteria. (50)

\section{Miswak (Salvadora Persica)}

Miswak, a twig of the Salvadora persica tree, shows an immediate antimicrobial effect on cariogenic bacteria esp. S. fecalis, S. mutans and Lactobacillus. (51) The miswak twig as a chewing stick appeared to be as effective as the toothbrush, if not more. (52) In addition, practicing the proper use of chewing stick as an oral hygiene aid, significantly lower plaque scores in comparison to the use of commonly used toothbrushes by inhibiting growth and acid production properties of cariogenic bacteria. $(53,54)$ The usage of chewing sticks can also assist in the reduction of gingival inflammation. However, chewing sticks can cause occlusal tooth wear and a small degree of gingival inflammation if used improperly or excessively. (55) It also possesses analgesic effect to thermal stimuli, thus, suggests effective in the management of dentinal hypersensitivity. (56) Gazi et al. found in his study that 
Miswak produce significant increases in calcium (22-fold), chloride (6-fold), significant decreases in phosphate and $\mathrm{pH}$ which lead to inhibition of demineralization and promotion of remineralization of tooth enamel because of the calcium saturation of saliva. (57)
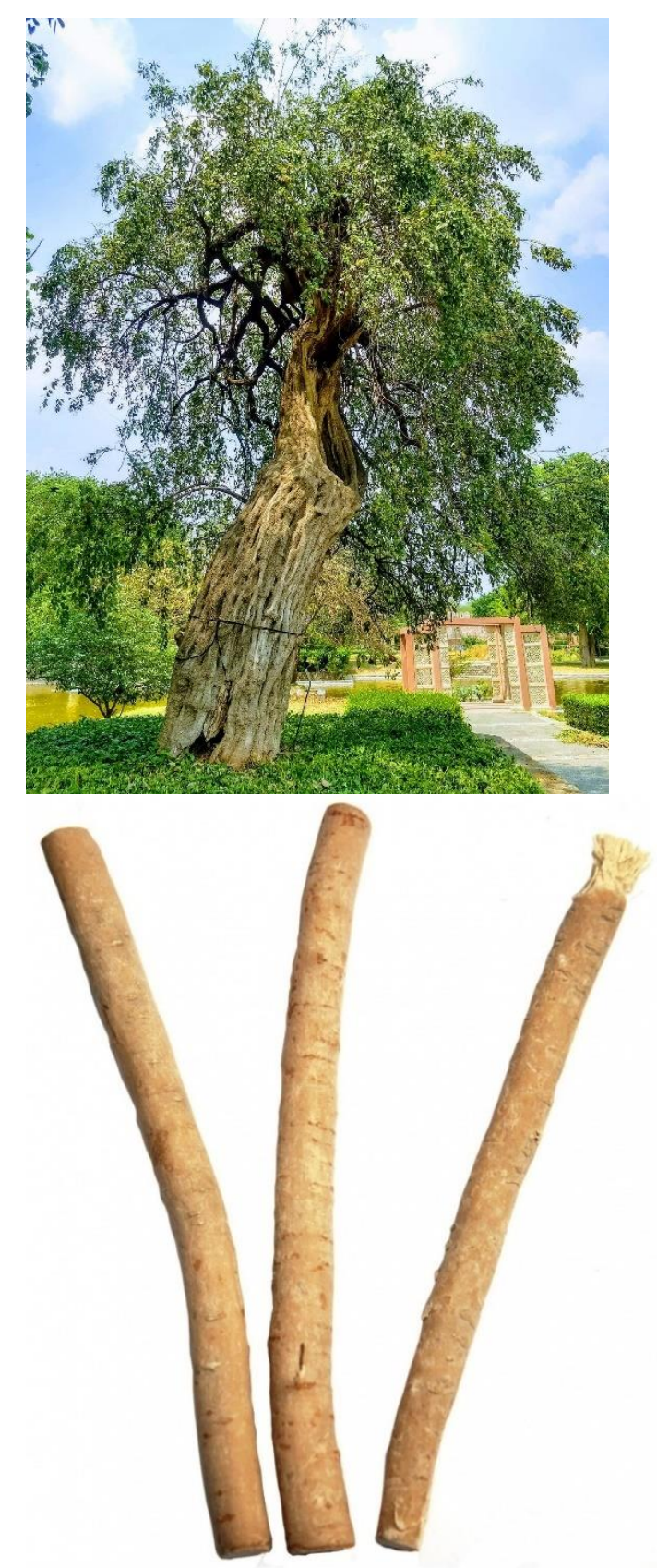

Figure. 3a: Salvadora persica (Miswak Tree); Figure. 3b: Miswak Toothbrush

\section{Aloe Vera}

Aloe Vera has been used since ancient times for its various medicinal values. Pure Aloe Vera juice and mouthwashes have role in reduction of dental plaques and plaque induced gingivitis. It destroys the plaque formation by bacteria called Streptococcus and prevents fermentation of oral fungi. (58) For patient suffering from oral lichen planus or oral ulcers, topical application of Aloe vera 3 times a day, provides pain relief, improves the oral lesions and the quality of life of patients. $(59,60)$ The Aloe Vera gel wound healing action is due to increased blood supply, which increases oxygenation as a result and stimulates fibroblast activity and collagen proliferation. $(61,62)$ Aloe vera shows antifungal actions against Candida albicans. Aloe vera leaf extracts can inhibit both the germ tube formation and hence the growth of $C$. albicans. $(63,64)$ It also shows antiviral action, a purified sample of Aloe emodin had effects on the infectivity of Herpes simplex virus type 1 and type 2, Varicella-Zoster virus, Pseudorabies virus, Influenza virus, Adenovirus, and Rhinovirus leading to their inactivation and disruption of the envelopes at the microscopic level. $(65,66)$

\section{Oregano (Origanum vulgare)}

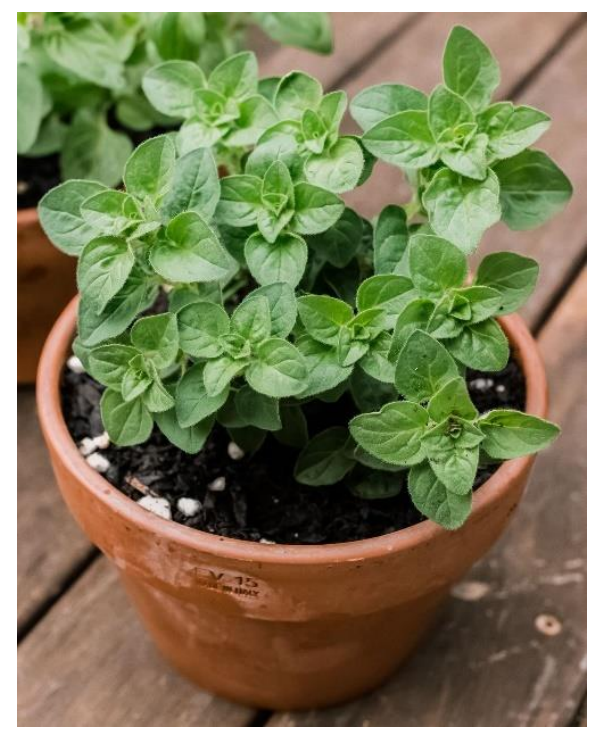

Figure. 4: Origanum vulgare (Oregano Plant)

Oregano essential oil is extracted from air-dried leaves and shoots of the plant Origanum vulgare and concentrated by steam distillation. (67) Oregano contains 
compounds like phenols, terpenes, and terpenoids. (68) Carvacrol is the most abundant phenol in oregano which shows potent antibacterial properties. (69) Thymol is the natural antifungal agent in oregano oil which supports the immune system and protects against toxins. (70) Rosmarinic acid is a powerful antioxidant that helps to guard against harm caused by free radicals. (71) In test-tube studies, it has been discovered that oregano essential oil is effective against five different types of Candida that cause infections within the mouth. (72) Test-tube studies conjointly found that carvacrol which is one of the main compounds of oregano oil is incredibly effective against oral Candida. (73) A test-tube study on the effectiveness of oregano essential oil on Sixteen different strains of Candida concluded that oregano oil may be a good alternative treatment for Candida yeast infections. (74) Avicenna in his book "The Canon of Medicine" mentioned that Oregano is a drug of choice for oral ulcers. Chewing oregano is effective in reducing bad breath odours. (75)

\section{Sesame (Sesamum indicum)}

Oil pulling or oil swishing has been used extensively as an ancient Ayurvedic remedy that has both dental and systemic effects. (76) Though the purported mechanism is unclear, the viscosity of the oil probably inhibits plaque coaggregation and bacterial adhesion.

Another possible mechanism might be a saponification process that occurs as a result of alkali hydrolysis of fat. (77) The sesame seed oil also contains lignans (sesamin, sesamolin, and sesamol) possessing anti-oxidant and healthpromoting properties. (78) Its antioxidant effect may detoxify toxins, potentiate the action of tocopherol (Vit. E), prevents oxidative degradation of lipids. (79)

It also has antibiotic effect i.e. it significantly reduces $S$. mutans counts in plaque and saliva within 1 week. (80)

\section{Garlic (Allium sativum)}

Garlic shows antibacterial effect against human dental plaque microbiota and the antibacterial activity of garlic is widely attributed to allicin (a compound that gives garlic its odour). $(81,82) S$. mutans is one of the most important oral bacteria which plays a major role in dental caries and bacteremia and garlic extract was found to inhibit and kill all oral streptococci strains tested. (83) The garlic solution mouthwash exhibited antimicrobial properties against oral microorganisms and streptococci in vivo. (84)

\section{Tulsi (Ocimum sanctum)}

Many research and studies suggest that due to its significant amount of eugenol, Tulsi may be a COX-2 inhibitor, like many modern painkillers. (85)

Tulsi is as an effective herbal mouth wash for treating bad breath, mouth ulcers and gum diseases because of its activity against Streptococcus mutans, the organism majorly responsible for tooth decay. (86) It is a preferred constituent for herbal mouth wash because of its taste and convenience as well. (87) In a study by Agarwal $\mathrm{P}$ and Nagesh L, rinsing with Tulsi resulted to be as effective as $0.2 \%$ Chlorhexidine and Listerine in reducing the levels of Streptococcus mutans. (88)

Tulsi demonstrated effective antimicrobial property against $A$. actinomycetemcomitans and $P$. gingivalis, so its use as an effective and affordable "adjunct" would be useful along with the standard care in the management of periodontal conditions. (89)

\section{Onion (Allium cepa)}

Toothache is often allayed by placing a small piece of onion on the tooth or gum. The anti-inflammatory agents (Vitamin C, Quercetin and active components like Isothiocyanates) in onions help reduce the severity of symptoms associated with conditions such as the pain and swelling. (90) Onion shows bactericidal properties 
and chewing raw onion for three minutes is sufficient to kill all the germs in the mouth. (91) Due to presence of Vitamin C, onions also strengthen and firm the gums. (92)

\section{Some Additional Herbs}

Mangiferin, a compound present in Mango leaves, possesses antibacterial activity in vivo against specific periodontal pathogens such as $P$. intermedia and $P$. gingivalis. (93) Eucalyptus Oil significantly retards biofilm formation, and thus can contribute to the development of novel anticaries treatments. (94) The ethanolic extracts of Guava leaves and Licorice roots produces anti-bacterial and anti-cariogenic activities against $S$. mutans. (95) Green Tea is effective in reducing acid production in dental plaque and mutans streptococci. (96) Amla (Phyllanthus emblica) is useful in ulcer prevention. (97) Cranberry reduces the formation of biofilms by $S$. mutans in vitro and dental caries development in vivo. (98) German Chamomile reduces both plaque accumulation and gingival inflammation. (99)

\section{Conclusion}

In this COVID-19 pandemic, providing proper dental care isn't an easy task for the dental professionals in many parts of the world because of the lack of protective equipment, these herbal alternatives can be very beneficial for the patients undergoing dental pain. WHO has also recommended for the incorporation of the traditional systems of medicine to be included into the primary health care system in those communities where it is accepted, such as Ayurveda. But these herbal home remedies are only useful in the symptomatic treatment and undergoing proper dental care is advised if it is feasible for the patient as well as the practitioner with full precautions.

\section{Acknowledgements}

Authors owe a debt of special thanks to the College of Dental Surgery, B.P. Koirala Institute of Health Sciences and their Teachers for the endless support and guidance throughout.

Financial Disclosure statement: The author received no specific funding for this work.

\section{Conflict of Interest}

The authors declare that there is no conflict of interest regarding the publication of this article.

\section{References}

1. Cohen LA, Bonito AJ, Akin DR, Manski RJ, Macek MD, Edwards RR, et. al. Toothache pain: Behavioral impact and self-care strategies. Special Care in Dentistry. 2009;29(2):85-95.

2. Matthews RW, Peak JD, Scully C. The efficacy of management of acute dental pain. British dental journal. 1994;176(11):413-6.

3. Brundha MP, Nallaswamy D. Hide and seek in pathology-A research on game-based histopathology learning. International Journal of Research in Pharmaceutical Sciences. 2019;10(2):1410-4.

4. Pavithra AS, Anjali AK. Home remedies for patients suffering from dental pain during lockdown-a questionnaire survey. International Journal of Research in Pharmaceutical Sciences. 2020;11(Special Issue 3).

5. Robinson MM, Zhang $X$. Traditional medicines: global situation, issues and challenges. The world medicines situation. 2011;1-14.

6. Kumar G, Jalaluddin MD, Rout P, Mohanty R, Dileep CL. Emerging trends of herbal care in dentistry. Journal of Clinical and Diagnostic Research: J Clin Diagn Res. 2013;7(8):1827.

7. Sujatha G, Muruganandhan J, Shamsudeen SM, Kumar S, Kumar N. Ayurveda in Dentistry- A Short Review. Journal of Clinical Dental Updates and Research. 2016;7(2):26-30

8. Meena AK, Rao MM. Folk herbal medicines used by the Meena community in Rajasthan. Asian journal of traditional medicines. 2010;5(1):19-31.

9. Kamboj A, Saluja A. Bryophyllum pinnatum (Lam.) Kurz.: phytochemical and pharmacological profile: a review. Pharmacognosy Reviews. 2009;3(6):364-374.

10. Van Wyk CW, Olivier A, De Miranda C, Van der Bijl P, Grobler-Rabie AF, Chalton DO. Effect of chilli (Capsicum frutescens) extract on proliferation of oral mucosal fibroblasts. 
Indian journal of experimental biology. 1995;33(4):244-248.

11. Cruz Martinez C, Diaz Gomez M, Oh MS. Use of traditional herbal medicine as an alternative in dental treatment in Mexican dentistry: a review. Pharmaceutical biology. 2017;55(1):1992-1998.

12. Kouadio F, Kanko C, Juge M, Grimaud N, Jean A, N'guessan YT, et. al. Analgesic and antiinflammatory activities of an extract from Parkia biglobosa used in traditional medicine in the Ivory Coast. Phytotherapy Research. 2000;14(8):635-637.

13. Megersa M, Jima TT, Goro KK. The use of medicinal plants for the treatment of toothache in Ethiopia. Evidence-Based Complementary and Alternative Medicine; 2019.

14. American Dental Association. Summary of ADA Guidance during the SARS-CoV-2 Crisis [Internet]. 2020. [cited 2021 Aug 15]. Available from: https://www.wsda.org/docs/librariesprovider52 /default-document-library/summary-of-adaguidance-during-the-sars-cov-2-crisis.pdf

15. American Dental Association. What constitutes a dental emergency? [Internet]. 2020. [cited 2021 Aug 15]. Available from: https://success.ada.org/ /media/CPS/Files/Ope n\%20Files/ADA_COVID19_Dental_Emergen cy_DDS.pdf

16. Steussy L. People are pulling their own teeth while dentists are on coronavirus lockdown. New York Post. [Internet]. 2020. [cited 2021 Aug 15]. Available from: https://nypost.com/2020/04/21/people-arepulling-their-own-teeth-with-dentists-onlockdown/

17. Pinto E, Vale-Silva L, Cavaleiro C, Salgueiro L. Antifungal activity of the clove essential oil from Syzygium aromaticum on Candida, Aspergillus and dermatophyte species. Journal of Medical Microbiology. 2009;58(11):14541462.

18. Chaieb K, Hajlaoui H, Zmantar T, KahlaNakbi AB, Rouabhia M, Mahdouani K, et. al. The chemical composition and biological activity of clove essential oil, Eugenia caryophyllata (Syzigium aromaticum L. Myrtaceae): a short review. Phytotherapy Research. 2007;21(6):501-506

19. Jirovetz L, Buchbauer G, Stoilova I, Stoyanova A, Krastanov A, Schmidt E. Chemical composition and antioxidant properties of clove leaf essential oil. Journal of Agricultural and Food Chemistry. 2006;54(17):6303-6307.

20. Devi KP, Nisha SA, Sakthivel R, Pandian SK. Eugenol (an essential oil of clove) acts as an antibacterial agent against Salmonella typhi by disrupting the cellular membrane. Journal of Ethnopharmacology. 2010;130(1):107-115.

21. International Organization for Standardization. Oil of clove leaf [Syzygium aromaticum (Linnaeus) Merril and Perry, syn. Eugenia caryophyllus (Sprengel) Bullock and S. Harrison]. "ISO-Directive 3141/1997, Geneva, Switzerland; 2002.

22. Bhati M, Duxbury AJ, Macfarlane TV, Downer MC. Analgesics recommended by dentists and pharmacists, and used by the general public for pain relief. International Journal of Health Promotion and Education. 2000;38(3):95-103.

23. Lee KG, Shibamoto T. Antioxidant property of aroma extract isolated from clove buds [Syzygium aromaticum (L.) Merr. et Perry]. Food Chemistry. 2001;74(4):443-448.

24. Moon SE, Kim HY, Cha JD. Synergistic effect between clove oil and its major compounds and antibiotics against oral bacteria. Archives of oral biology. 2011;56(9):907-916.

25. Aneja KR, Joshi R. Antimicrobial activity of Syzygium aromaticum and its bud oil against dental cares causing microorganisms. Ethnobotanical Leaflets. 2010;14:960-975.

26. Prashar A, Locke IC, Evans CS. Cytotoxicity of clove (Syzygium aromaticum) oil and its major components to human skin cells. Cell Proliferation. 2006;39(4):241-248.

27. Khan MY, Panchal S, Vyas N, Butani A, Kumar V. Olea europaea: a phytopharmacological review. Pharmacognosy Reviews. 2007;1(1):114-118.

28. Kumar S, Tiwari MM, Gautam SS. Antimicrobial and phytochemical screening of Olea europaea Linn. extracts against dental pathogens. African Journal of Microbiology Research. 2014;8(37):3373-3377.

29. Karygianni L, Cecere M, Argyropoulou A, Hellwig E, Skaltsounis AL, Wittmer A, et. al. Compounds from Olea europaea and Pistacia lentiscus inhibit oral microbial growth. BMC Complementary and Alternative Medicine. 2019;19(1):1-10.

30. Cai JN, Kim MA, Jung JE, Pandit S, Song KY, Jeon JG. Effects of combined oleic acid and fluoride at sub-MIC levels on EPS formation and viability of Streptococcus mutans UA159 biofilms. Biofouling. 2015;31(7):555-563.

31. Ayoub AO, Awooda EM. Evaluation of the effectiveness of olive oil on the prevention of dental erosion: An In vitro study. Journal of Dental Research and Review. 2019;6(4):88.

32. Wiegand A, Gutsche M, Attin T. Effect of olive oil and an olive-oil-containing fluoridated mouthrinse on enamel and dentin erosion in vitro. Acta Odontologica Scandinavica. 2007;65(6):357-361. 
33. Golestannejad Z, Khozeimeh F, Abtahi R, Zarei Z, Sadeghalbanaei L, Sadeghian R. Inhibitory effects of ethanolic, methanolic, and hydroalcoholic extracts of olive (Olea europaea) leaf on growth, acid production, and adhesion of Streptococcus mutans. Dental Research Journal. 2020;17(3):179.

34. Gazi MI. The finding of antiplaque features in Acacia Arabica type of chewing gum. Journal of Clinical Periodontology. 1991;18(1):75-77.

35. Clark DT, Gazi MI, Cox SW, Eley BM, Tinsley GF. The effects of Acacia arabica gum on the in vitro growth and protease activities of periodontopathic bacteria. Journal of Clinical Periodontology. 1993;20(4):238-243.

36. Tangade PS, Mathur A, Tirth A, Kabasi S. Anti-gingivitis effects of Acacia arabicacontaining toothpaste. Chinese Journal of Dental Research. 2012;15(1):49.

37. Singhal R, Agarwal V, Rastogi P, Khanna R, Tripathi S. Efficacy of Acacia arabica gum as an adjunct to scaling and root planing in the treatment of chronic periodontitis: A randomized controlled clinical trial. The Saudi Dental Journal. 2018;30(1):53-62.

38. Chaturvedi TP. Uses of turmeric in dentistry: an update. Indian J Dent Res. 2009;20(1):1079.

39. Cikrikci S, Mozioglu E, Yilmaz H. Biological activity of curcuminoids isolated from Curcuma longa. Records of Natural Products. 2008;2(1):19.

40. Waghmare PF, Chaudhari AU, Karhadkar VM, Jamkhande AS. Comparative evaluation of turmeric and chlorhexidine gluconate mouthwash in prevention of plaque formation and gingivitis: A clinical and microbiological study. J Contemp Dent Pract. 2011;12(4):221224.

41. Suhag A, Dixit J, Dhan P. Role of curcumin as a subgingival irrigant: a pilot study. Periodontal Practice Today. 2007;4(2):115-21.

42. Das DA, Balan A, Sreelatha KT. Comparative study of the efficacy of curcumin and turmeric oil as chemopreventive agents in oral submucous fibrosis: A clinical and histopathological evaluation. Journal of Indian Academy of Oral Medicine and Radiology. 2010;22(2):88.

43. Lone PA, Wakeel Ahmed S, Prasad V, Ahmed B. Role of turmeric in management of alveolar osteitis (dry socket): A randomised clinical study. Journal of Oral Biology and Craniofacial Research. 2018;8(1):44-47.

44. Pandit S, Kim HJ, Kim JE, Jeon JG. Separation of an effective fraction from turmeric against Streptococcus mutans biofilms by the comparison of curcuminoid content and anti-acidogenic activity. Food Chemistry. 2011;126(4):1565-1570.
45. Sharma A, Ahlawat B, Sharma S. Turmeric-Its Applications in Dentistry. J Adv Res Med. 2016;3(1):27-30.

46. Wilken R, Veena MS, Wang MB, Srivatsan ES. Curcumin: A review of anti-cancer properties and therapeutic activity in head and neck squamous cell carcinoma. Molecular Cancer. 2011;10(1):12.

47. Debjit Bhowmik C, Kumar KS, Chandira M, Jayakar B. Turmeric: a herbal and traditional medicine. Archives of Applied Science Research. 2009;1(2):86-108.

48. Prashant GM, Chandu GN, Murulikrishna KS, Shafiulla MD. The effect of mango and neem extract on four organisms causing dental caries: Streptococcus mutans, Streptococcus salivavius, Streptococcus mitis, and Streptococcus sanguis: An in vitro study. Indian Journal of Dental Research. 2007;18(4):148.

49. Azenha C, Ruela RS, Queiroz DB, Ruela WS, Marinho G, Ruela FI. Efficacy of a mouthrinse based on leaves of the neem tree (Azadirachta indica) in the treatment of patients with chronic gingivitis: A double-blind, randomized, controlled trial. Journal of medicinal plants research. 2008;2(11):341346.

50. Baswa M, Rath CC, Dash SK, Mishra RK. Antibacterial activity of Karanj (Pongamia pinnata) and Neem (Azadirachta indica) seed oil: a preliminary report. Microbios. 2001;105(412):183-189.

51. Bhat PK, Kumar A, Sarkar S. A Comparative Clinical Study to Assess the Immediate Antimicrobial Effect of Miswak and Toothbrush on Cariogenic Bacteria. World Applied Sciences Journal. 2011;15(6):899903.

52. Olsson B. Efficiency of traditional chewing sticks in oral hygiene programs among Ethiopian school children. Community Dentistry and Oral Epidemiology. 1978;6(3):105-109.

53. Wu CD, Darout IA, Skaug N. Chewing sticks: timeless natural toothbrushes for oral cleansing. Journal of periodontal research. 2001;36(5):275-284.

54. Ababneh H. The effect of the extract of the miswak (chewing sticks) used in Jordan and the Middle East on oral bacteria. International Dental Journal. 1995;45(3):218-222.

55. Gazi M, Saini T, Ashri N, Lambourne A. Meswak chewing stick versus conventional toothbrush as an oral hygiene aid. Clinical preventive dentistry. 1990;12(4):19.

56. Al-Khateeb TL, Al-Mazraoo AA. The analgesic effect of Miswak. Saudi Dent J. 1996;8:87-91. 
57. Gazi MI, Davies TJ, AI-Bagieh N, Cox SW. The immediate-and medium-term effects of Meswak on the composition of mixed saliva. Journal of Clinical Periodontology. 1992;19(2):113-117.

58. Swerdlow JL. Medicine Changes: late 19th to early 20th century. Nature's Medicine: Plants that Heal. 2000;110-191.

59. Radwan-Oczko M. Topical application of drugs used in treatment of oral lichen planus lesions. Adv Clin Exp Med. 2013;22(6):893-8.

60. Salazar-Sánchez N, López-Jornet P, CamachoAlonso F, Sánchez-Siles M. Efficacy of topical Aloe vera in patients with oral lichen planus: a randomized double-blind study. Journal of oral pathology \& medicine. 2010;39(10):735-740.

61. Yagi A, Egusa T, Arase M, Tanabe M, Tsuji $H$. Isolation and characterization of the glycoprotein fraction with a proliferationpromoting activity on human and hamster cells in vitro from Aloe vera gel. Planta Medica. 1997;63(01):18-21.

62. Davis RH, Leitner MG, Russo JM, Byrne ME. Anti-inflammatory activity of Aloe vera against a spectrum of irritants. Journal of the American Podiatric Medical Association. 1989;79(6):263-276.

63. Doddanna SJ, Patel S, Sundarrao MA, Veerabhadrappa RS. Antimicrobial activity of plant extracts on Candida albicans: an in vitro study. Indian Journal of Dental Research. 2013;24(4):401.

64. Bernardes I, Felipe Rodrigues MP, Bacelli GK, Munin E, Alves LP, Costa MS. Aloe vera extract reduces both growth and germ tube formation by Candida albicans. Mycoses. 2012;55(3):257-261.

65. Sydiskis RJ, Owen DG, Lohr JL, Rosler KH, Blomster RN. Inactivation of enveloped viruses by anthraquinones extracted from plants. Antimicrobial agents and chemotherapy. 1991;35(12):2463-2466.

66. Andersen DO, Weber ND, Wood SG, Hughes BG, Murray BK, North JA. In vitro virucidal activity of selected anthraquinones and anthraquinone derivatives. Antiviral Research. 1991;16(2):185-196.

67. Kula J, Majda T, Stoyanova A, Georgiev E. Chemical composition of Origanum vulgare $\mathrm{L}$. essential oil from Bulgaria. Journal of Essential Oil Bearing Plants. 2007;10(3):215220.

68. Veenstra JP, Johnson JJ. Oregano (Origanum vulgare) extract for food preservation and improvement in gastrointestinal health. International Journal of Nutrition. 2019;3(4):43.

69. Nostro A, Papalia T. Antimicrobial activity of carvacrol: current progress and future prospectives. Recent patents on anti-infective drug discovery. 2012;7(1):28-35.

70. De Castro RD, de Souza TMPA, Bezerra LMD, Ferreira GLS, de Brito Costa EMM, Cavalcanti AL. Antifungal activity and mode of action of thymol and its synergism with nystatin against Candida species involved with infections in the oral cavity: an in vitro study. BMC complementary and alternative medicine. 2015;15(1):1-7.

71. Bakota EL, Winkler-Moser JK, Berhow MA, Eller FJ, Vaughn SF. Antioxidant activity and sensory evaluation of a rosmarinic acidenriched extract of Salvia officinalis. Journal of Food Science. 2015;80(4):C711-C717.

72. Pozzatti P, Scheid LA, Spader TB, Atayde ML, Santurio JM, Alves SH. In vitro activity of essential oils extracted from plants used as spices against fluconazole-resistant and fluconazole-susceptible Candida spp. Canadian Journal of Microbiology. 2008;54(11):950956.

73. Marcos-Arias C, Eraso E, Madariaga L, Quindós G. In vitro activities of natural products against oral Candida isolates from denture wearers. BMC Complementary and Alternative Medicine. 2011;11(1):119.

74. Cleff MB, Meinerz AR, Xavier M, Schuch LF, Meireles MCA, Rodrigues MRA, et al. In vitro activity of Origanum vulgare essential oil against Candida species. Brazilian Journal of Microbiology. 2010;41(1):116-123.

75. Avicenna. The Canon of Medicine: Book II. 1025.

76. Saravanan D, Ramkumar S, Vineetha K. Effect of oil pulling with sesame oil on plaqueinduced gingivitis: A microbiological study. Journal of Orofacial Research. 2013;175-180.

77. Namiki M. The chemistry and physiological functions of sesame. Food Reviews International. 1995;11(2):281-329.

78. Kato MJ, Chu A, Davin LB, Lewis NG. Biosynthesis of antioxidant lignans in Sesamum indicum seeds. Phytochemistry. 1998;47(4):583-591

79. Hebbar A, Keluskar V, Shetti A. Oil pullingUnraveling the path to mystic cure. J Int Oral Health. 2010;2(4):11-15.

80. Selvam PP, Nandan N, Raj S. Oil Pulling-A Blessing in Disguise. Journal of Ayurveda and Integrated Medical Sciences. 2017;1(4):08-13.

81. Houshmand B, Mahjour F, Dianat O. Antibacterial effect of different concentrations of garlic (Allium sativum) extract on dental plaque bacteria. Indian Journal of Dental Research. 2013;24(1):71.

82. Bayan L, Koulivand PH, Gorji A. Garlic: a review of potential therapeutic effects. Avicenna Journal of Phytomedicine. 2014;4(1):1 
83. Tanzer JM, Livingston J, Thompson AM. The microbiology of primary dental caries in humans. Journal of Dental Education. 2001;65(10):1028-1037.

84. Groppo FC, Ramacciato JC, Motta RHL, Ferraresi PM, Sartoratto A. Antimicrobial activity of garlic against oral streptococci. International Journal of Dental Hygiene. 2007;5(2):109-115

85. Tewari D, Sah AN, Pandey HK, Meena HS, Meena R, Ramaswamy RS, et. al. A review on phytoconstituents of Ocimum (Tulsi). International Journal of Ayurvedic Medicine. 2012;3(1):1-9.

86. Malik K, Arora G, Singh I. Ocimum sanctum seeds, a natural superdisintegrant: Formulation and evaluation of fast melt tablets of nimesulide. Polim Med. 2012;42(1):49-59.

87. Malhotra R, Grover V, Kapoor A, Saxena D. Comparison of the effectiveness of a commercially available herbal mouthrinse with chlorhexidine gluconate at the clinical and patient level. Journal of Indian Society of Periodontology. 2011;15(4):349.

88. Agarwal P, Nagesh L. Comparative evaluation of efficacy of $0.2 \%$ Chlorhexidine, Listerine and Tulsi extract mouth rinses on salivary Streptococcus mutans count of high school children-RCT. Contemporary clinical trials. 2011;32(6):802-808.

89. Jayanti I, Jalaluddin M, Avijeeta A, Ramanna PK, Rai PM, Nair RA. In vitro Antimicrobial Activity of Ocimum sanctum (Tulsi) Extract on Aggregatibacter actinomycetemcomitans and Porphyromonas gingivalis. The Journal of Contemporary Dental Practice. 2018;19(4):415-419.

90. Smith C, Lombard KA, Peffley EB, Liu W. Genetic Analysis of Quercetin in Onion (Allium cepa L.) 'Lady Raider'. Texas Journal of Agriculture and Natural Resources. 2003;16:24-28.

91. Kim JH. Anti-bacterial action of onion (Allium cepa L.) extracts against oral pathogenic bacteria. The Journal of Nihon University School of Dentistry. 1997;39(3):136-141.

92. Mahant S, Thakur SK. Home remedies for dental diseases in the Pandemic of COVID-19 - A Systematic Review. Journal of Advanced Medical and Dental Sciences Research. 2020;8(6):39-44.

93. Bairy I, Reeja S, Rao PS, Bhat M, Shivananda PG. Evaluation of antibacterial activity of Mangifera indica on anaerobic dental microglora based on in vivo studies. Indian Journal of Pathology \& Microbiology. 2002;45(3):307-310.

94. Rasooli I, Shayegh S, Astaneh SDA. The effect of Mentha spicata and Eucalyptus camaldulensis essential oils on dental biofilm.
International Journal of Dental Hygiene. 2009;7(3):196-203.

95. Phaiboon N, Pulbutr P, Sungthong B, Rattanakiat S. Effects of the Ethanolic Extracts of Guava Leaves, Licorice Roots and Cloves on the Cariogenic Properties of Streptococcus mutans. Pharmacognosy Journal. 2019;11(5).

96. Hirasawa M, Takada K, Otake S. Inhibition of acid production in dental plaque bacteria by green tea catechins. Caries Research. 2006;40(3):265-270.

97. Grover HS, Deswal H, Singh Y, Bhardwaj A. Therapeutic effects of amla in medicine and dentistry: A review. Journal of Oral Research and Review. 2015;7(2):65.

98. Koo H, Duarte S, Murata RM, Scott-Anne K, Gregoire S, Watson GE, et. al. Influence of cranberry proanthocyanidins on formation of biofilms by Streptococcus mutans on salivacoated apatitic surface and on dental caries development in vivo. Caries Research. 2010;44(2):116-126.

99. Pourabbas R, Delazar A. The effect of German chamomile mouthwash on dental plaque and gingival inflammation. Iranian Journal of Pharmaceutical Research. 2010;(2):105-109. 